\title{
Does Growth Affect the Nature of Inequality?
}

\author{
Ireland 1994-2001 ${ }^{1}$
}

\author{
Aedín Doris*, Donal O’Neill ${ }^{* *} \&$ Olive Sweetman*
}

\begin{abstract}
Much has been written about the relationship between economic growth and aggregate inequality in recent years. In this paper we extend this literature by examining whether economic growth affects, not the level, but rather the nature of inequality. To do this we focus on the Irish economy which experienced a remarkable boom starting in 1994. We analyse the covariance structure of earnings in Ireland to examine whether this rapid growth affected earnings dynamics over the period. Using panel data for the years 1994-2001, we show that, while permanent inequality in Ireland is high, the degree of persistence of inequality was not significantly affected by the rapid growth in the economy.
\end{abstract}

JEL Classification: J31

Keywords: Permanent and Transitory Inequality.

\footnotetext{
${ }^{1}$ We would like to thank Daniele Checchi, Xavi Ramos, Gary Solon and participants at seminars at NUI Maynooth, Universitat Autonoma de Barcelona, and the Irish Economic Association Annual Conference for helpful comments on an earlier draft of this paper and Donal Smith for his excellent research assistance. We also gratefully acknowledge the financial support provided by the Irish Research Council for the Humanities and Social Sciences.

${ }^{* *}$ Department of Economics, National University of Ireland, Maynooth and IZA, Bonn.

${ }^{*}$ Department of Economics, National University of Ireland, Maynooth.
} 


\section{Introduction}

Much has been written on the relationship between growth and aggregate inequality. The Kuznets hypothesis (Kuznets 1955), for example, suggests that inequality increases over the initial stages of development as the economy moves from agricultural to industrial, but then falls as the labour force in industry expands. More recently there has been a large literature on the impact of technological progress on inequality. ${ }^{2}$ However, for the most part the empirical literature (e.g. Easterly (1999), Dollar and Kray (2002)) has been unable to find a significant effect of growth on inequality.

However, all of this literature has focused on aggregate measures of inequality. A growing literature has emerged in recent years which aims to decompose overall inequality into two distinct components: inequality that reflects differences across individuals or groups that are due to permanent characteristics (so called 'permanent' inequality) and inequality arising from temporary shocks, which cause disadvantage at a point in time but have limited persistence over time ('transitory' inequality).

The motivation for these decompositions was to develop a better understanding of the growth in earnings inequality experienced by many countries in recent decades. Some explanations of this growth have focussed on the apparently pervasive increases in the returns to education, argued to be due to skill-biased technological change or increasing international trade ${ }^{3}$ explanations of this type would suggest the growth of permanent inequality. Other analyses have emphasized

\footnotetext{
${ }^{2}$ For a recent discussion of the relationship between technological progress and inequality see Iacopetta (2005).

${ }^{3}$ For a discussion of returns to education in Ireland, see Barrett et al. (2002).
} 
increasing lifetime earnings instability for given individuals, perhaps due to an increasing susceptibility of earnings to the competitive pressures faced by firms. To the extent that increased lifetime inequality translates into an increased variance of earnings at any given point in time, this would increase overall inequality.

The matter of which of these two components of inequality has been responsible for increasing the overall level of inequality also has important policy implications. A high or increasing role for permanent inequality requires a reduction in the dispersion of permanent characteristics, such as education levels, if inequality is to be reduced. On the other hand, if transitory inequality is primarily responsible for increasing inequality, then an emphasis on skills will have little effect, and attention might be more usefully paid to other features of the labour market, such as employment protection legislation. In fact, most studies have found that both permanent and transitory components have contributed to growing inequality (cf. Gottschalk and Moffit (1995) and Haider (2001) for the US; Kalwij and Alessie (2007), Dickens (2000) and Ramos (2003) for the UK; Gustavsson (2007) for Sweden; Baker and Solon (2003) for Canada).

In this paper we extend the earlier work that looks at the impact of growth on inequality by examining, not whether growth affects the level of aggregate inequality, but rather whether it affects the underlying nature of inequality. To do this we examine the evolution of inequality in Ireland over the years 1994-2001. The Irish case is of interest because of the transformation that occurred over this period. 1994 saw the start of a remarkable economic boom, with average annual GDP growth rates of $8.5 \%$. The impact on unemployment rates is shown in Figure 1. Unemployment fell from $14.7 \%$ to $3.6 \%$ between 1994 and 2001 . Unemployment had not fallen below $12.9 \%$ in the previous decade and stabilised after 2001, making our choice of sample 
period particularly relevant. Employment growth was even more striking, with total employment rising by $41 \%$ during that time, fuelled by increasing participation rates, particularly for women, but also by high net positive inward migration for the first time in the country's history. There is also evidence that job mobility increased significantly during the period: Bergin (2008, Table 3) reports that the number of workers changing jobs in the previous year increased from $5.7 \%$ in 1995 to $10.2 \%$ in 2001.

With such a striking increase in labour market activity, it might be expected that fundamental changes in the functioning of the labour market also took place. For example, market forces might be expected to be stronger in a tight labour market, inducing firms to change their wage-setting mechanisms. Workers, too, might encounter more frequent opportunities for changing their situations. Thus, it might be expected that a boom of this length and intensity would increase the importance of the transitory component of inequality. Establishing whether the changing labour market did indeed have an effect on the nature of inequality in Ireland is the primary focus of this paper.

A secondary focus of the paper concerns the proportion of inequality that is permanent. Daly and Valetta (2007) provide tentative evidence of an inverse relationship between the level of overall inequality and the proportion of that inequality that is permanent. They decompose inequality in Germany, the US and the UK into its permanent and transitory components and find that the permanent component is lower in the US (an average of 53.6\%) and the UK (average 51.2\%) where overall inequality in higher - than in Germany (average 57.8\%). ${ }^{4}$ This accords with the view that high inequality countries are also countries of high mobility, with

\footnotetext{
${ }^{4}$ Jenkins and Van Kerm (2006), using a different methodology, also find that the impact of reranking, which is a feature of transitory shocks, was much larger in the US in the 1980's than in Germany, leading to a greater increase in inequality in the US.
} 
the implication that a lower proportion of overall inequality is permanent in these countries. The analysis of Irish data can provide another data point in assessing the validity of this suggestion. The level of inequality in Ireland is high by international standards and is similar to that in the US and the UK, rather than continental or northern Europe. For example, Nolan (2000, Table 6.2) gives the Irish 90/10 earnings ratio in 1994 as 4.06; this compares with 4.35 in the US, 3.31 in the UK, 3.28 in France, 2.32 in Germany and 2.13 in Sweden; of the sixteen countries listed in the table, only the US has higher earnings dispersion.

To address these issues, we decompose inequality in Ireland into its permanent and transitory components, using the European Community Household Panel (ECHP) data, which is available from 1994 to 2001. We consider the proportion of total inequality accounted for by the permanent component and look for any evidence of a trend in this component over this period.

The methodology is outlined in Section 2; the data are discussed in Section 3; results are presented in Section 4. Section 5 reports the results for the extension of the analysis to public and private sector earnings and our conclusions are presented in Section 6.

\section{Methodology}

To model earnings over the life-cycle we write log-earnings as a function of labourmarket experience, $X_{i t}$ and a residual, $y_{i t}$ :

$$
\log Y_{i t}=g\left(X_{i t}, \delta_{t}\right)+y_{i t}
$$


In addition we assume that the residual component, $y_{i t}$, can be written as the sum of a permanent component, $\alpha_{i}$, due for example to fixed characteristics such as the level of education, and a transitory one, $v_{i t}$, reflecting temporary shocks that affect the individual or the labour market. That is

$$
y_{i t}=\alpha_{i}+v_{i t}
$$

where $\alpha_{i}$ and $v_{i t}$ are random variables with mean zero and variances $\sigma_{\alpha}^{2}$ and $\sigma_{v t}^{2}$ respectively. Our objective is to identify the separate roles played by the permanent and transitory shocks in determining inequality. To do this we first estimate $y_{i t}$ by calculating the residuals from OLS regressions of equation (1). ${ }^{5}$ These residuals are then used to model the covariance structure described by equation (2). Modelling the dynamics of earnings through the residual term allows us to abstract from any common growth trends or life-cycle effects.

We use two approaches to estimate the relative contributions of permanent and transitory shocks. The first approach, which we loosely describe as the 'nonparametric' approach, uses data from two time periods $t$ and $s$, that are sufficiently far apart that $\operatorname{Cov}\left(v_{i t}, v_{i s}\right)=0$. In this case the variance of the permanent component is identified from the covariance of earnings, $\operatorname{Cov}\left(y_{i t}, y_{i s}\right)=\sigma_{\alpha}^{2}$, and the proportion of total inequality that is permanent is given by

$$
\frac{\operatorname{Cov}\left(y_{i t}, y_{i s}\right)}{\operatorname{Var}\left(y_{i t}\right)}
$$

However, this approach relies on some arbitrary assumptions about the evolution of individual earnings. In particular, it assumes that that the returns to permanent characteristics accounted for by $\alpha_{i}$ are constant over time and also that the

\footnotetext{
${ }^{5}$ In the empirical application $g$ is a simple quadratic in experience.
} 
persistence of transitory shocks is of an order no higher than $s-t$. To examine the robustness of our findings to these assumptions, we also consider an alternative approach that models these features explicitly using a parametric model of earnings dynamics.

In the parametric model, we write $y_{i t}$ as:

$$
y_{i t}=p_{t} \alpha_{i}+\lambda_{t} v_{i t}
$$

where $p_{t}$ and $\lambda_{t}$ are factor loadings that allow the permanent and temporary variances of earnings respectively to change over time. To allow for persistence in the transitory shocks, we specify a model for $v_{i t}$. We considered a number of alternatives processes but the preferred specification is based on the assumption that $v_{i t}$ follows an ARMA $(1,1)$ process, that is

$$
v_{i t}=\rho v_{i t-1}+\theta \varepsilon_{i t-1}+\varepsilon_{i t} .
$$

where the $\varepsilon_{i t}$ are i.i.d. random error terms with mean zero and variance $\sigma_{\varepsilon}^{2}$. In the model given by (4) and (5), and with eight years of data (described below), there are 19 parameters to estimate $\left(\sigma_{\alpha}^{2}, \rho, \lambda_{2}-\lambda_{8}, p_{2}-p_{8}, \sigma_{v 0}^{2}, \sigma_{\varepsilon}^{2}, \theta\right)^{6}$. We denote this parameter vector by $\gamma$. We estimate these parameters using a Generalized Method of Moments (GMM) estimator. Intuitively, this entails choosing the parameters of the model so that the moments of the theoretical model outlined in (4) and (5) are matched as closely as possible to their empirical counterparts.

To do this, the residuals, $y_{i t}$, are used to calculate the empirical variancecovariance matrix for the eight years, $\hat{C}$. The corresponding population variance-

\footnotetext{
${ }^{6}$ For identification, we normalise $\lambda_{I}$ and $p_{I}$ to 1.
} 
covariance matrix is denoted by $C$. In (4) and (5) above, the variance-covariance matrix $C=f(\gamma)$ has the typical diagonal element:

$$
\operatorname{Var}\left(y_{t}\right)=p_{t}^{2} \sigma_{\alpha}^{2}+\lambda_{t}^{2}\left(\rho^{2 t} \sigma_{v 0}^{2}+K \sum_{w=0}^{t-1} \rho^{2 w}\right)
$$

and typical off-diagonal element,

$$
\operatorname{Cov}\left(y_{t,} y_{t+s}\right)=p_{t} p_{t+s} \sigma_{\alpha}^{2}+\lambda_{t} \lambda_{t+s}\left(\rho^{2 t+s} \sigma_{v o}^{2}+\rho K \sum_{w=0}^{t-1} \rho^{2 w}+\theta \sigma_{\varepsilon}^{2}\right)
$$

where $K=\sigma_{\varepsilon}^{2}\left(1+\theta^{2}+2 \rho \theta\right)$.

Once $C=f(\gamma)$ has been specified, the parameter vector $\hat{\gamma}$ is then chosen to minimize $(\hat{C}-f(\hat{\gamma}))^{\prime} W(\hat{C}-f(\hat{\gamma}))$, where $W$ is a weighting matrix (Chamberlain, 1984). Following Altonji and Segal (1996), we set $W$ equal to the identity matrix, $I$. In our model there are 19 parameters to estimate and $36(T(T+1) / 2)$ unique moment conditions. Because of the nature of the panel data used, the calculation of standard errors is not straightforward; we followed the procedure outlined in Appendix A of Haider (2001) and in Haider (2000). ${ }^{7}$

\section{Data}

The data used in the analysis are the eight waves of Irish data in the European Community Household Panel (ECHP), which contains data on 14 EU countries. These are the only panel data with appropriate earnings variables available for Ireland. The years covered by the survey are 1994-2001.

\footnotetext{
${ }^{7}$ We are grateful to Steve Haider for providing a copy of the unpublished 2000 paper.
} 
In the Irish data, the initial sample size in 1994 was 9,904 individuals; falling to 4,023 in $2001 .^{8}$ The sample chosen for the present study is comprised of men aged 21-65 whose labour market behaviour does not indicate characteristics likely to be associated with erratic earnings. Thus, anyone who experiences unemployment or time out of the labour market on 'home duties' at any stage during the sample period is omitted from the sample altogether. Anyone not reporting earnings in any year for which he was employed is also dropped from the sample, as is anyone with earnings data missing due to attrition. This use of a balanced panel follows the approach taken in Haider (2001), Baker and Solon (2003), Baker (1997), Daly and Valetta (2007) and Gustavsson (2007).

Considering a balanced panel of males allows us to assess the effect of the boom on the nature of the labour market only, and to abstract from any changes in the composition of the labour force. Given that unemployment dropped significantly during the sample period after a long period of very high unemployment, and particularly when it is considered that in $1994,65 \%$ of unemployed men were longterm unemployed, it is very likely that the characteristics - both observed and unobserved - of those who re-joined the labour market as the boom progressed were very different to those who had been working all along. Similarly, the participation rate of women rose from $39 \%$ to $47.5 \%$ during the period, with composition effects likely if women who entered the labour market after many years of absence were included.

The effect of the changes in the composition of the labour force on inequality in Ireland is a very interesting topic, and is one that will be addressed in future work,

\footnotetext{
${ }^{8}$ This reflects substantial sample attrition in the Irish data but Watson (2003) concludes that although there are some correlations between attrition and economic variables, such correlation explains only a very small part of the attrition.
} 
but for now, we wish to focus on any changes in the way the labour market operates, rather than conflating these changes with changes in the workforce.

The sample is not, however, a fully balanced panel, but rather a 'revolving' balanced panel. Individuals are allowed to be in the sample for some years but not for others if their absence is due to retirement, being in full-time education, or failure to meet the age restriction. The assumption here is that retirement or schooling are not indicative of either stability or instability in labour market attachment. Of course, younger workers are known to have more earnings instability than older workers, but this appears to be due to time taken to find a good job match rather than lack of labour market attachment.

Outliers, defined as earnings in the top or bottom $1 \%$ of the sample distribution, are also excluded. Finally, the sample was restricted to those who had at least two years of observed earnings in the sample, in order to reduce the difference between the samples used to calculate the variances and those used to calculate the autocovariances.

In order to illustrate the effects of these various sample selection rules on measured inequality, as well as to give a picture of overall inequality in Ireland during the sample period, Figure 2 shows the coefficient of variation of earnings for men aged 21-65 before and after the sample selection rules were applied. It also shows, for completeness, the variance of the residuals calculated from Equation (1). It can be seen that the pattern of inequality, as measured by the coefficient of variation of gross earnings, is similar in the two samples, but that both falls and rises are more muted in the revolving balanced panel sample. 


\section{Results}

For each year of data, current monthly log gross earnings are regressed on potential experience and its square, as described above, and the residuals saved. The variancecovariance matrix of these residuals is reported in Table 1. Looking along the diagonal, we observe that despite the rapid growth in the economy over the period, the variance is relatively stable over the period, ranging from a high of 0.217 in 1994 to a low of 0.173 in 1996 . Looking down each column, the autocovariances decline over time, with the most significant decline at the first order; after the first period, there is a smooth, but very gradual decline. A similar pattern has been found by many other authors, including, for example, Daly and Valetta (2007), for the US, Germany and the UK; Haider (2001) for the US; Baker and Solon (2003) for Canada; and Gustavsson (2004) for Sweden.

As a preliminary estimate of the proportion of inequality that is due to permanent factors, we use the non-parametric estimate given by (2) above. Following Moffitt and Gottschalk (2002), we choose covariances that are five years apart to estimate $\operatorname{Var}\left(\alpha_{i}\right)$. Given the short panel available, the required covariances can only be calculated for three pairs of years $(1994 / 1999,1995 / 2000$ and 1996/2001). These indicate that in 1994, the permanent component of inequality was $67 \%$ of the total; in 1995 , the figure was $69 \%$ and in 1996 , permanent inequality was $77 \%$ of the total. These figures are suggestive of a rise in permanent inequality, but with estimates for only three years available, no significance can be read into the trend. Our results are not directly comparable with many other studies because of differences in the time periods used. However Daly and Valetta (2007) use data for the 1990s. Using their 
variance-covariance matrix, ${ }^{9}$ the non-parametric estimate indicates that the permanent component lies between $48 \%$ and $53 \%$ for Great Britain, with values for West Germany ranging between $56 \%$ and $70 \%$ and for the US between $60 \%$ and $67 \%$, all for the early 1990s. Thus we see that the Irish values are at the upper range of estimates found for other countries.

To examine the nature of Irish inequality in more detail, we estimate the parametric model outlined in Section 2. These results are presented in Table 2. $\rho$, the parameter indicating the degree of persistence of transitory shocks, is estimated to be 0.64 , and $\theta$ is estimated to be -0.23 , which reduces the magnitude of the first order correlations. The results show no clear pattern in either the $\lambda_{t}$, the factor loadings on the transitory shocks, or in the $p_{t}$, the factor loadings on the permanent characteristics. None of these is individually significantly different from one at the $5 \%$ confidence level, and Wald tests also fail to reject the hypotheses that the $p_{t}$ 's are jointly equal to one, or that the $\lambda_{t}$ 's are jointly equal to one, so there is no evidence of any trend. We return to this issue in the next section.

The parameter estimates can also be used to calculate permanent inequality, transitory inequality and predicted total inequality. The decomposition results are presented in Table 3 and graphed in Figure 3. Looking at the first two columns of Table 3, we see that the model does well in predicting the actual total variance. Of more interest is the relative importance of the transitory and permanent components in total inequality, which is given in the last column of the table. At the beginning of the period, permanent inequality accounted for approximately $63 \%$ of total earnings

\footnotetext{
${ }^{9} \mathrm{We}$ are grateful to Robert Valetta for providing us with the unpublished variance-covariance matrix used in the Daly and Valetta study.
} 
inequality. In subsequent years, it rose to about $77 \%$ (1997). The average over the whole period is about $71 \%$. It is striking how similar these estimates are to the nonparametric one reported above.

Although it can be difficult to compare studies across different countries because of differences in time period, sample construction, and measures of earnings, as well as in the details of the models of earnings dynamics used, it is interesting nevertheless to try and compare our results to previous studies. In doing so we restrict our comparisons where possible to studies that use a similar methodology to the one we adopt. Haider (2001) finds that permanent inequality accounts for on average, about two-thirds of total variance in the US between 1968-1992. Baker and Solon (2003) conduct a similar analysis for Canada from 1976-1992, and find that the permanent component fell from about $70 \%$ to $64 \%$ over that period. Gustavsson's (2007) results indicate that permanent inequality varied between approximately 63$70 \%$ for males aged 40 in Sweden during the 1990s. Cervini and Ramos (2006) find that the permanent component for Spain varies substantially by age cohort, but for men born from 1954-1963, it rose from about 60\% to about $75 \%$ between 1993 and 2001. Moffitt and Gottschalk (2002) find the permanent component varying from about $37 \%$ to about $63 \%$ over the $1969-1996$ period in the US. And Ramos (2003) reports a permanent component that averages about $40 \%$ during the 1990 s in Britain.

The study that is the most similar to ours is, however, Daly and Valetta (2007). As mentioned previously, their parametric analysis implies a permanent contribution of 54\% for the US, 58\% for Germany and 52\% for Great Britain over the 1990's. Thus our estimate of $71 \%$ is at the upper end of the range of previous 
estimates, and is particularly high in the most relevant comparison. ${ }^{10}$ These results suggest that Ireland suffers from both a high level of overall earnings inequality, and a high proportion of that inequality being permanent, suggesting low earnings mobility. However, there is no evidence that the rapid growth experienced during this period altered the nature of inequality.

\section{Centralized Wage Bargaining and Public and Private Sector Earnings}

The fact that we find no change in the proportion of inequality that is permanent over the sample period is somewhat surprising, given the labour market changes in Ireland outlined in Section 1. One possible explanation for this result is the highly centralized nature of wage bargaining in Ireland. As explained in greater detail below, the way wage bargaining is conducted means that it is plausible that any forces acting to reduce permanent inequality would be stronger in the private sector than in the public sector. Thus, this section carries out a decomposition of inequality separately for these two sectors, after first explaining the wage bargaining system.

Centralized wage bargaining in its current form, known as 'Social Partnership', was introduced in $1987^{11}$ and since then, agreements have been negotiated every two or three years between employer organisations, trade unions and the government to award fixed percentage wage increases to employees at set dates. Higher percentage awards are typically made to very low-paid workers.

Because the wage agreements are specified in terms of percentage increases that should be awarded by any given employer, they serve to 'freeze' the pre-existing

\footnotetext{
${ }^{10}$ See also Gangl (2005) who uses a different methodology but also concludes that permanent inequality is high in Ireland

${ }^{11}$ This was in response to a serious fiscal crisis. Wage restraint was the primary goal in the early years; in exchange for low bargained wage increases, the government committed to reducing the income tax burden, so that net pay increases could be achieved without damaging competitiveness.
} 
wage distribution in place. Thus, if there is some external force encouraging an increase in inequality - such as skill-biased technical change or increasing international trade - the pay agreement system will indeed reduce inequality below what it would otherwise be, as suggested by Gottschalk and Joyce (1998), amongst others. However, it is interesting to note that any external force reducing inequality would be resisted by the wage bargaining system.

Moreover, in the absence of job changes, the wage bargaining system would freeze not only the overall distribution, but also the position of individuals within that distribution. Thus, we expect that the system leads to a higher proportion of permanent inequality than would otherwise prevail.

In practice, however, the agreements may have less 'bite' than suggested by the above description. Firstly, not all employees are covered, as not all employers are aligned with the employers' organisations. Secondly, employees can move jobs in order to escape wage restraint; since negotiated wage increases apply to posts that already exist within an organisation, it is open to an employee to move between employers and secure a 'promotion' through the distribution.

Thirdly, as the labour market became increasingly tight during the economic boom, employers began to give 'top-up' wage increases to retain staff. Compliance with early wage agreements was reported to be very high, even in the multinational sector where employers are typically not affiliated with employers' organisations, and unions are weak. However, by 2000, there were widespread reports of top-ups being awarded. It is important to note, however, that public sector employees would have been firmly bound by the agreements; as one of the three major players in the negotiations of the agreements, the government could not be seen to be breaking its own terms, even in the face of labour shortages in some sectors. If top-ups were 
offered independently of permanent characteristics, this would lead us to expect that the proportion of inequality that was permanent would be falling for private sector workers, but not for public sector workers, towards the end of the sample period. On the other hand, if top-ups were correlated with permanent characteristics, no reduction in permanent inequality would be expected.

The above analysis suggests that the boom may have affected the functioning of the private sector labour market, and increasingly so as time went on, but this effect may have been obscured by the fact that centralized wage bargaining prevented any such effect in the public sector labour market. Thus, in this section, we report results of the decomposition of public and private sector earnings inequality into permanent and transitory components.

Tables 4 and 5 give the covariance matrices for public and private sector earnings respectively. In constructing these matrices, the sample was initially constructed exactly as before - individuals who were missing earnings data for any year that they were not either in education or in retirement were excluded, as were those outside the 21-65 age range. Earnings in the top and bottom $1 \%$ of the full sample's distribution (i.e. public and private sector earnings together) were also dropped. It was at this stage that the sample was separated into observations on public sector and private sector earnings. At that point, any individual who did not have at least two years of earnings in the relevant sector was dropped. It is important to note that individuals who moved from one sector to the other and had at least two years of recorded earnings in each sector will be present in both samples. Thus, this is an analysis of public and private sector earnings, rather than public and private sector workers. 
Looking at the variance-covariance matrix for public sector earnings in Table 4, its most striking characteristic is how much lower the variances (along the diagonal) are than in Table 1, the equivalent table for all workers. There is no obvious trend in the variances, which range from 0.127 in 1998 to 0.146 in 2001 , with a typical value of about 0.139 . This compares with a typical value of about 0.187 for all workers. In general, however, the same pattern of autocovariances holds as before the biggest drop is in the one-period covariances, with smaller drops - and indeed some small rises - thereafter. For the private sector variance-covariance matrix given in Table 5, the variances are very similar to those in Table 1 , as is the pattern of covariances. However, the sharp contrast with Table 4, for public sector earnings, is clear. In 1994, the variance of private sector earnings was 0.240 , whereas that for public sector earnings was 0.145 ; in 2001 , the variances were 0.190 and 0.146 respectively. Thus, wage dispersion is, unsurprisingly, significantly lower in the public sector than in the private sector.

The non-parametric estimates of the proportion of total inequality that is permanent in the two sectors also reveal sharp differences. In the public sector, $81 \%$ of inequality is estimated to be permanent in $1994,82 \%$ in 1995 and $80 \%$ in 1996 . In contrast, the permanent proportion in the private sector is estimated to be $60 \%$ in 1994, 58\% in 1995 and 74\% in 1996. Thus, public sector earnings are less dispersed, but more persistent than private sector earnings; the distribution is less unequal, but once assigned a place in the distribution, it is more difficult to change rank within the distribution. 
We had difficulty estimating the full model outlined in Section 2 when the data was split into public and private sectors. ${ }^{12}$ We did however obtain robust results for a restricted version of the model with fewer factor loadings. In particular we allow the permanent and transitory variances to change between 1994-1997 and 1998-2001 but restrict them to be constant within these periods. While this limits our ability to identify trends, it does allow us to examine the extent to which the absence of a trend in the full sample was driven by the stricter adherence to centralized wage bargaining in the public sector. The results are presented in Table 6 , where for comparison we also present the two factor model for all workers. The estimated proportion of variance that is permanent for all workers is $71.3 \%$, which is almost identical to the results from the more general eight factor model presented in Section 4.

Looking at the results for the private and public sector we still find no evidence of a significant change in the nature of inequality over the sample period. This is not surprising for the public sector. However, the absence of a trend in the private sector suggests that the centralized wage bargaining system cannot explain our earlier findings.

We also present the predictions of the permanent proportion for the public and private sectors in Tables 7 and 8 respectively. The decomposition of inequality into its permanent and transitory component is consistent with the non-parametric results above. For the public sector, the permanent component accounts for $78 \%$ of the total variance on average over the sample period, while the corresponding figure for the private sector is $64 \%$. This confirms the view that while inequality is lower in the public sector, the wage distributions are much more rigid with little mobility within

\footnotetext{
${ }^{12}$ In particular, some of the parameter estimates, such as $\rho$, were not robust to changes in starting values and seemed to be affected by a small number of moment conditions.
} 
the distribution. This would accord with expectations, given that pay progression occurs almost exclusively along pre-determined 'pay scales' in the public sector. It also concurs with conclusions drawn by Postel-Vinay and Turon (2005) and Cappellari (2002) about public sector earnings in Britain and Italy respectively.

\section{Conclusions}

This paper extends previous work examining the impact of growth on inequality by considering the impact of growth on the nature, rather than the level, of inequality. We do this by examining inequality in Ireland for the years 1994-2001. Ireland experienced a remarkable boom over this time period, with average annual growth rates of $8.5 \%$. Our analysis of the covariance structure of earnings in Ireland suggests that the degree of persistence of Irish inequality is high, with permanent inequality accounting for about $71 \%$ of total inequality. However we find no evidence that the underlying nature of inequality in Ireland was greatly affected by the rapid growth over this period. Our analysis of the private and public sectors shows that although earnings inequality is significantly lower in the public than in the private sector, the permanent component is much higher. However, again, we discern no significant time trend in the proportion of inequality that is permanent, in either the public or private sectors. 


\section{References}

Baker, Michael (1997). 'Growth Rate Heterogeneity and Covariance Structure of Life-Cycle Earnings', Journal of Labor Economics, Vol 15, No. 2, pp. 338-375.

Baker, Michael and Gary Solon (2003). 'Earnings Dynamics and Inequality among Canadian Men, 1976-1992: Evidence from Longitudinal Income Tax Records', Journal of Labor Economics, Vol. 21, No. 2, pp. 289-321.

Barrett, A. J. FitzGerald and B. Nolan (2002). 'Earnings Inequality, Returns to Education and Immigration in Ireland', Labour Economics, Vol. 9, No. 5.

Bergin, Adele (2008), 'Job Mobility in Ireland,' mimeo NUI Maynooth.

Cappellari ,L. (2002) 'Earnings Dynamics and Uncertainty in Italy: How do they differ between the Private and Public Sectors?' Labour Economics, Vol 9 pp477-496

Cappellari ,L. (2004) 'The Dynamics and Inequality of Italian Men's Earnings: LongTerm Changes or Transitory Fluctuations?' Journal of Human Resources Vol 39(2) pp 475-499

Cervini, Maria and Xavier Ramos (2008). 'Long-Term Earnings Inequality, Earnings Instability and Temporary Employment in Spain 1993-2000'IZA Working Paper 3538.

Chamberlain, Gary, (1984). 'Panel Data' in Z. Griliches and M.D. Intriligator (eds.), Handbook of Econometrics, Amsterdam: Elsevier.

Daly, Mary and Robert Valletta (2008). 'Cross-National Trends in Earnings Inequality and Instability', Economic Letters, Vol 99 no 2 pp 215-219.

Dollar, D. and A. Kraay (2002), ' Growth is Good for the Poor' Journal of Economic Growth, Vol. 7, pp. 195-225.

Dickens, R. (2000), 'The Evolution of Individual Male Earnings in Great Britain: 1975-95, Economic Journal Vol 110 pp27-49.

Easterly, W (1999), ' Life During Growth: International Evidence on Quality of life and Per Capita Income,' Journal of Economic Growth, no. 4, pp. 239-276.

Gangl, M. (2005). 'Income Inequality, Permanent Incomes and Income Dynamics', Income Dynamics, Vol. 32, No.2, pp. 140-162.

Gottschalk, Peter and Mary Joyce (1998). 'Cross-National Differences in the Rise in Earnings Inequality: Market and Institutional Factors', Review of Economics and Statistics, Vol. 80, No. 4, pp. 489-502.

Gottschalk, Peter and Robert Moffitt (1995). 'Trends in the Covariance Structure of Earnings in the US: 1969-1987'. Working Paper, John Hopkins University. 
Gustavsson, Magnus (2004). 'Trends in the Transitory Variance of Earnings: Evidence from Sweden 1960-1990 and a Comparison with the United States', Working Paper 2004:11, Uppsala University.

Gustavsson, Magnus (2007). 'The 1990s Rise in Swedish Earnings Inequality Persistent or Transitory?', Applied Economics, Vol. 39, pp. 25-30.

Haider, Steven J. (2000). 'Generalized Method of Moments with Incomplete Data: Estimating Earnings Dynamics Models’, Unpublished Manuscript, RAND.

Haider, S J. (2001), 'Earnings Instability and Earnings Inequality of Males in the United States: 1967-1991', Journal of Labor Economics, Vol. 19, No 4, pp. 799-836.

Icopetta, M (2005), 'Technological Progress and Inequality: An Ambiguous Relationship' available at SSRN http://ssrn.com/abstract=822964.

Jenkins, S. and P. Van Kerm (2006), 'Trends in Income Inequality, pro-poor Income Growth, and Income Inequality,' Oxford Economic Papers, Vol. 58, pp. 531-548.

Kalwij, Adriaan \& R. Alessie " Permanent and Transitory Wages of British Men, 1975-2001: Year, Age and Cohort Effects", Journal of Applied Econometrics Vol 22 pp 1063-1093.

Kuznets, S (1955), 'Economic Growth and Inequality,' American Economic Review, no. 45 , pp. $1-28$.

Moffitt, Robert and Peter Gottschalk (2002). 'Trends in the Transitory Variance of Earnings in the United States', Economic Journal, Vol.112, pp. 68-73.

Nolan, B. (2000). 'The Distribution of Earnings', Chapter 6 in B. Nolan, B. Maitre, D. O'Neill and O. Sweetman, The Distribution of Income in Ireland, Dublin: Combat Poverty Agency.

Postel-Vinay, F and H. Turon (2005). 'The Public Pay Gap in Britain: Small Differences that (Don't) Matter', CMPO Working paper, no. 05/121.

Ramos, Xavier (2002). 'The Covariance Structure of Earnings in Great Britain, 19911999’, Economica, Vol. 70, pp. 353-374.

Watson, Dorothy (2003). 'Sample Attrition Between Waves 1 and 5 in the European Community Household Panel', European Sociological Review, Vol. 19, No. 4, pp. 361-378. 
Table 1: Variance-Covariance Matrix of Residuals from Regressions of Monthly Gross Earnings on Experience, Male Employees. Cell sizes in italics

\begin{tabular}{|l|l|l|l|l|l|l|l|l|}
\hline & 1994 & 1995 & \multicolumn{1}{|c|}{1996} & 1997 & 1998 & 1999 & 2000 & 2001 \\
\hline 1994 & .2174 & & & & & & & \\
& 435 & & & & & & & \\
\hline 1995 & .1748 & .1924 & & & & & & \\
& 432 & 439 & & & & & & \\
\hline 1996 & .1541 & .1566 & .1729 & & & & & \\
& 426 & 430 & 436 & & & & & \\
\hline 1997 & .1506 & .1537 & .1560 & .1812 & & & & \\
& 418 & 422 & 426 & 433 & & & & \\
\hline 1998 & .1414 & .1462 & .1469 & .1532 & .1775 & & \\
& 408 & 411 & 416 & 419 & 427 & & & \\
\hline 1999 & .1465 & .1406 & .1421 & .1475 & .1572 & .1807 & & \\
& 404 & 407 & 412 & 416 & 420 & 430 & & \\
\hline 2000 & .1317 & .1301 & .1320 & .1393 & .1428 & .1467 & .1875 & \\
& 395 & 398 & 403 & 407 & 412 & 421 & 424 & \\
\hline 2001 & .1372 & .1324 & .1337 & .1417 & .1403 & .1465 & .1555 & .1854 \\
& 392 & 395 & 398 & 403 & 406 & 416 & 418 & 421 \\
\hline
\end{tabular}


Table 2: Parameter Estimates: Monthly Gross Earnings, 21-65 Male Employees

\begin{tabular}{|c|c|c|}
\hline Parameters & Estimate & SE \\
\hline$\sigma_{\alpha}^{2}$ & 0.1377 & .0166 \\
\hline$\rho$ & 0.6351 & .1280 \\
\hline \multicolumn{3}{|c|}{$\begin{array}{l}\text { Factor Loadings - Transitory Shock } \\
\left(\lambda_{t}\right)\end{array}$} \\
\hline 1994 & 1 & \\
\hline 1995 & 0.9471 & .1153 \\
\hline 1996 & 0.8144 & .1228 \\
\hline 1997 & 0.8455 & .1293 \\
\hline 1998 & 0.8697 & .1395 \\
\hline 1999 & 0.8646 & .1224 \\
\hline 2000 & 1.0938 & .1628 \\
\hline 2001 & 0.9856 & .1588 \\
\hline \multicolumn{3}{|c|}{$\begin{array}{l}\text { Factor Loadings - Permanent Shock } \\
\left(p_{t}\right)\end{array}$} \\
\hline 1994 & 1 & \\
\hline 1995 & 0.9833 & .0382 \\
\hline 1996 & 0.9791 & .0507 \\
\hline 1997 & 1.0026 & .0575 \\
\hline 1998 & 0.9846 & .0708 \\
\hline 1999 & 0.9941 & .0675 \\
\hline 2000 & 0.9263 & .0690 \\
\hline 2001 & 0.9709 & .0683 \\
\hline$\sigma_{v}^{2}$ & 0.1121 & .0559 \\
\hline$\overline{\sigma_{\varepsilon}^{2}}$ & 0.0453 & .0130 \\
\hline$\theta$ & -0.2298 & .1038 \\
\hline
\end{tabular}


Table 3: Trends in Permanent and Transitory Inequality in Ireland 1994-2001 Male Employees Age 21-65

\begin{tabular}{|l|l|l|l|l|l|}
\hline Year & Actual & $\begin{array}{l}\text { Predicted } \\
\text { Variance }\end{array}$ & $\begin{array}{l}\text { Transitory } \\
\text { Inequality }\end{array}$ & $\begin{array}{l}\text { Persistent } \\
\text { Inequality }\end{array}$ & $\begin{array}{l}\text { Proportion of } \\
\text { inequality due to } \\
\text { Permanent } \\
\text { component }\end{array}$ \\
\hline 1994 & .2175 & .2174 & .0797 & .1377 & .6334 \\
\hline 1995 & .1924 & .1930 & .0598 & .1332 & .6902 \\
\hline 1996 & .1729 & .1727 & .0407 & .1320 & .7643 \\
\hline 1997 & .1812 & .1808 & .0424 & .1385 & .7657 \\
\hline 1998 & .1775 & .1777 & .0442 & .1335 & .7514 \\
\hline 1999 & .1807 & .1795 & .0434 & .1361 & .7582 \\
\hline 2000 & .1875 & .1875 & .0693 & .1182 & .6304 \\
\hline 2001 & .1854 & .1860 & .0562 & .1298 & .6979 \\
\hline
\end{tabular}


Table 4: Variance-Covariance Matrix of Residuals from Regressions of Monthly Gross Public Sector Earnings on Experience, Males 21-65. Cell sizes in italics

\begin{tabular}{|l|l|l|l|l|l|l|l|l|}
\hline & 1994 & 1995 & \multicolumn{1}{|c|}{1996} & 1997 & 1998 & 1999 & 2000 & 2001 \\
\hline 1994 & .1452 & & & & & & & \\
\hline 1995 & .1258 & .1441 & & & & & & \\
& 205 & 209 & & & & & & \\
\hline 1996 & .1179 & .1251 & .1296 & & & & & \\
& 202 & 205 & 209 & & & & & \\
\hline 1997 & .1123 & .1165 & .1115 & .1376 & & & & \\
& 183 & 185 & 189 & 195 & & & \\
\hline 1998 & .1130 & .1166 & .1103 & .1142 & .1268 & & & \\
& 177 & 178 & 180 & 178 & 188 & & & \\
\hline 1999 & .1182 & .1181 & .1092 & .1156 & .1224 & .1411 & & 179 \\
& 167 & 169 & 171 & 169 & 173 & 183 & & \\
\hline 2000 & .1157 & .1188 & .1128 & .1179 & .1155 & .1149 & .1406 & \\
& 158 & 158 & 160 & 158 & 164 & 164 & 171 & \\
\hline 2001 & .1089 & .1064 & .1036 & .1092 & .1069 & .1104 & .1182 & .1460 \\
& 162 & 162 & 165 & 165 & 167 & 169 & 165 & 169 \\
\hline
\end{tabular}


Table 5: Variance-Covariance Matrix of Residuals from Regression of Monthly Gross Private Sector Earnings on Experience, Males 21-65. Cell sizes in italics

\begin{tabular}{|l|l|l|l|l|l|l|l|l|}
\hline & 1994 & \multicolumn{1}{|c|}{1995} & \multicolumn{1}{|c|}{1996} & 1997 & 1998 & 1999 & 2000 & 2001 \\
\hline 1994 & $\begin{array}{l}.2396 \\
225\end{array}$ & & & & & & & \\
\hline 1995 & .1808 & .1958 & & & & & & \\
& 221 & 229 & & & & & & \\
\hline 1996 & .1564 & .1518 & .1813 & & & & & \\
& 216 & 221 & 226 & & & & & \\
\hline 1997 & .1454 & .1451 & .1596 & .1887 & & & & \\
& 212 & 215 & 218 & 233 & & & & \\
\hline 1998 & .1372 & .1422 & .1545 & .1621 & .1870 & & & \\
& 207 & 211 & 213 & 222 & 235 & & & \\
\hline 1999 & .1446 & .1345 & .1500 & .1524 & .1604 & .1924 & & \\
& 204 & 209 & 211 & 220 & 225 & 242 & & \\
\hline 2000 & .1148 & .1142 & .1262 & .1386 & .1475 & .1580 & .2040 & \\
& 202 & 206 & 206 & 217 & 222 & 234 & 246 & \\
\hline 2001 & .1315 & .1190 & .1337 & .1412 & .1454 & .1591 & .1614 & .1898 \\
& 200 & 203 & 204 & 214 & 216 & 227 & 230 & 236 \\
\hline
\end{tabular}


Table 6: Parameter Estimates: Monthly Gross Earnings, Public and Private Sector and All Employees, Males 21-65. Standard Errors in Parentheses

\begin{tabular}{|c|c|c|c|}
\hline Parameters & All & Public & Private \\
\hline$\sigma_{\alpha}^{2}$ & $\begin{array}{l}0.1338 \\
(.0140)\end{array}$ & $\begin{array}{l}.1083 \\
(.0183)\end{array}$ & $\begin{array}{l}.1178 \\
(.0208)\end{array}$ \\
\hline$\rho$ & $\begin{array}{l}0.5952 \\
(.1244)\end{array}$ & $\begin{array}{l}.6945 \\
(.3765)\end{array}$ & $\begin{array}{l}.6092 \\
(.1249)\end{array}$ \\
\hline $\begin{array}{l}\text { Factor Loadings - Transitory } \\
\text { Shock }\left(\lambda_{t}\right)\end{array}$ & & & \\
\hline$\lambda_{1} 1994-1998$ & 1 & 1 & 1 \\
\hline$\lambda_{2} 1996-1997$ & $\begin{array}{l}1.1065 \\
(.0846)\end{array}$ & $\begin{array}{l}1.1121 \\
(.1378)\end{array}$ & $\begin{array}{l}.9907 \\
(.0923)\end{array}$ \\
\hline $\begin{array}{l}\text { Factor Loadings - Permanent } \\
\text { Shock }\left(p_{t}\right)\end{array}$ & & & \\
\hline$p_{1} 1994-1995$ & 1 & 1 & 1 \\
\hline$p_{2} 1996-1997$ & $\begin{array}{l}.9925 \\
(.0371)\end{array}$ & $\begin{array}{l}1.0016 \\
(.0500)\end{array}$ & $\begin{array}{l}1.0569 \\
(.0657)\end{array}$ \\
\hline$\sigma_{v}^{2}$ & $\begin{array}{l}0.1570 \\
(.0502)\end{array}$ & $\begin{array}{l}0.0547 \\
(.0267)\end{array}$ & $\begin{array}{l}0.2082 \\
(.0679)\end{array}$ \\
\hline$\sigma_{\varepsilon}^{2}$ & $\begin{array}{l}0.0338 \\
(.0040)\end{array}$ & $\begin{array}{l}.0220 \\
(.0053)\end{array}$ & $\begin{array}{l}.0453 \\
(.0057)\end{array}$ \\
\hline$\theta$ & $\begin{array}{l}-0.2140 \\
(.1381)\end{array}$ & $\begin{array}{l}-.4812 \\
(.3340)\end{array}$ & $\begin{array}{l}-.1220 \\
(.1543)\end{array}$ \\
\hline
\end{tabular}


Table 7: Trends in Permanent and Transitory Inequality in Ireland 1994-2001

Public Sector Earnings, Male Employees 21-65 2 factor model

\begin{tabular}{|c|c|c|c|c|c|}
\hline Year & $\begin{array}{l}\text { Actual } \\
\text { Variance }\end{array}$ & $\begin{array}{l}\text { Predicted } \\
\text { Variance }\end{array}$ & $\begin{array}{l}\text { Transitory } \\
\text { Inequality }\end{array}$ & $\begin{array}{l}\text { Persistent } \\
\text { Inequality }\end{array}$ & $\begin{array}{l}\text { Proportion of } \\
\text { inequality due to } \\
\text { Permanent } \\
\text { component }\end{array}$ \\
\hline 1994 & .1452 & .1471 & .0388 & .1083 & .7365 \\
\hline 1995 & .1441 & .1394 & .0311 & .1083 & .7771 \\
\hline 1996 & .1296 & .1357 & .0274 & .1083 & .7984 \\
\hline 1997 & .1376 & .1339 & .0256 & .1083 & .8090 \\
\hline 1998 & .1268 & .1392 & .0306 & .1087 & .7805 \\
\hline 1999 & .1411 & .1387 & .0300 & .1087 & .7834 \\
\hline 2000 & .1406 & .1385 & .0298 & .1087 & .7848 \\
\hline 2001 & .1460 & .1384 & .0297 & .1087 & .7855 \\
\hline
\end{tabular}


Table 8: Trends in Permanent and Transitory Inequality in Ireland 1994-2001

Private Sector Earnings, Males 21-65

\begin{tabular}{|l|l|l|l|l|l|}
\hline Year & Actual & Predicted & Transitory & Persistent & Proportion of \\
Variance & Inequality & Inequality & $\begin{array}{l}\text { (nequality due to } \\
\text { Permanent } \\
\text { component }\end{array}$ \\
\hline 1994 & .2396 & .2343 & .1166 & .1178 & .5026 \\
\hline 1995 & .1958 & .2003 & .0825 & .1178 & .5879 \\
\hline 1996 & .1813 & .1877 & .0699 & .1178 & .6275 \\
\hline 1997 & .1887 & .1830 & .0652 & .1178 & .6436 \\
\hline 1998 & .1870 & .1939 & .0623 & .1316 & .6786 \\
\hline 1999 & .1924 & .1933 & .0617 & .1316 & .6808 \\
\hline 2000 & .2040 & .1930 & .0615 & .0316 & .6816 \\
\hline 2001 & .1898 & .1929 & .0614 & .0316 & .6819 \\
\hline
\end{tabular}


Figure 1. Unemployment Rates in Ireland (\%), 1983-2008.

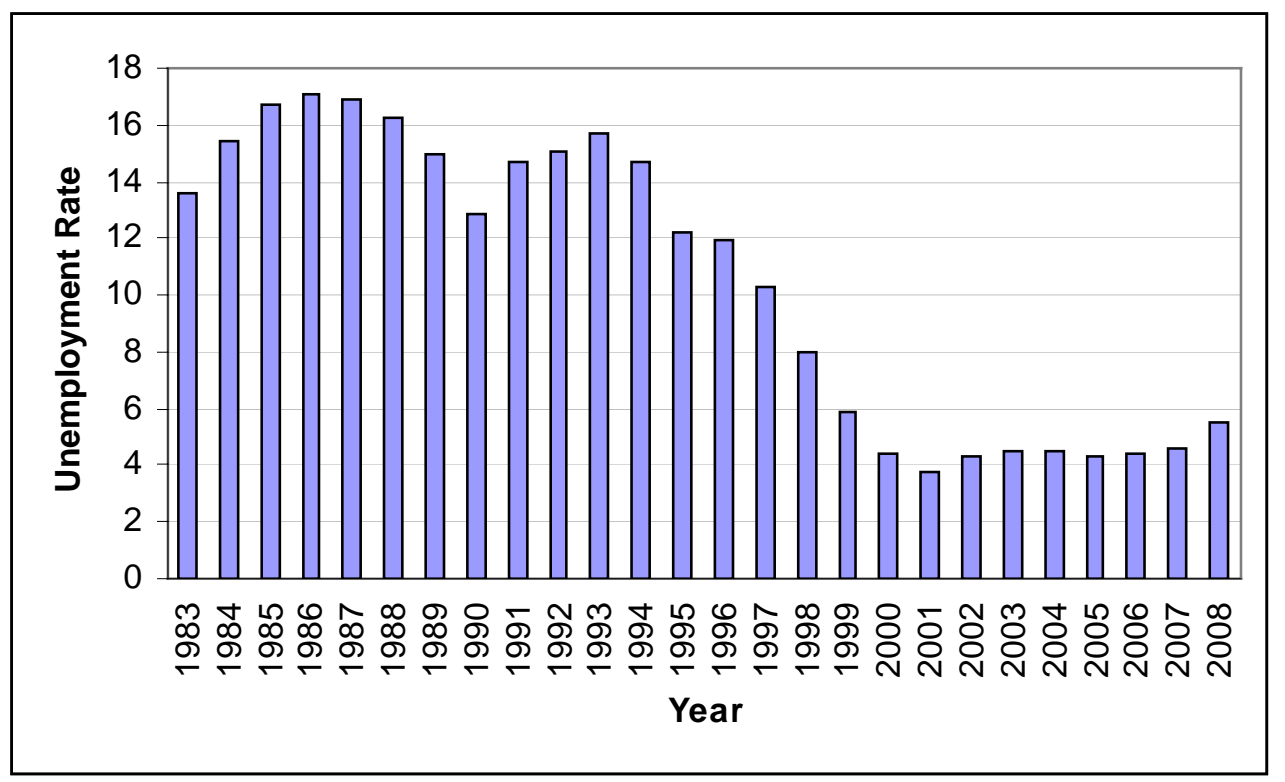

Figure 2. Earnings Inequality for Males aged 21-65, Unbalanced Sample and Revolving Balanced Panel Sample.

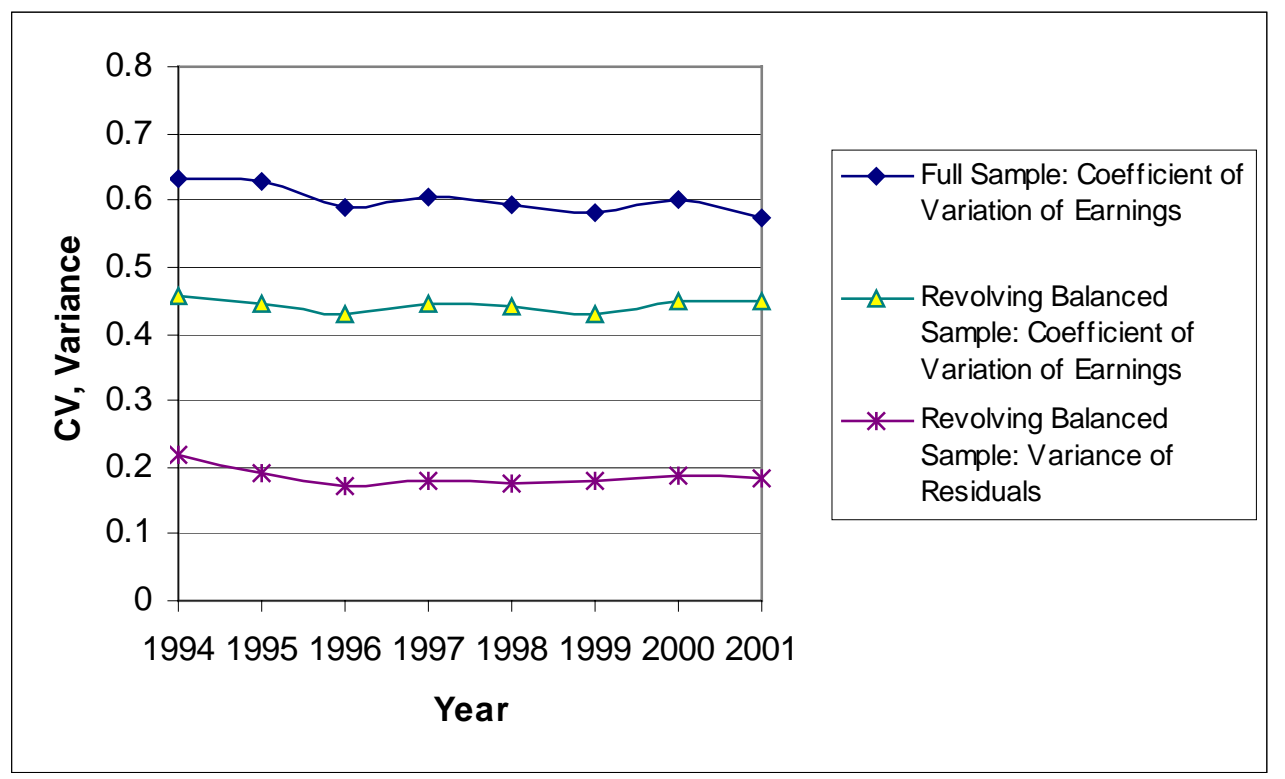


Figure 3. Decomposition of Earnings Inequality Males aged 21-65.

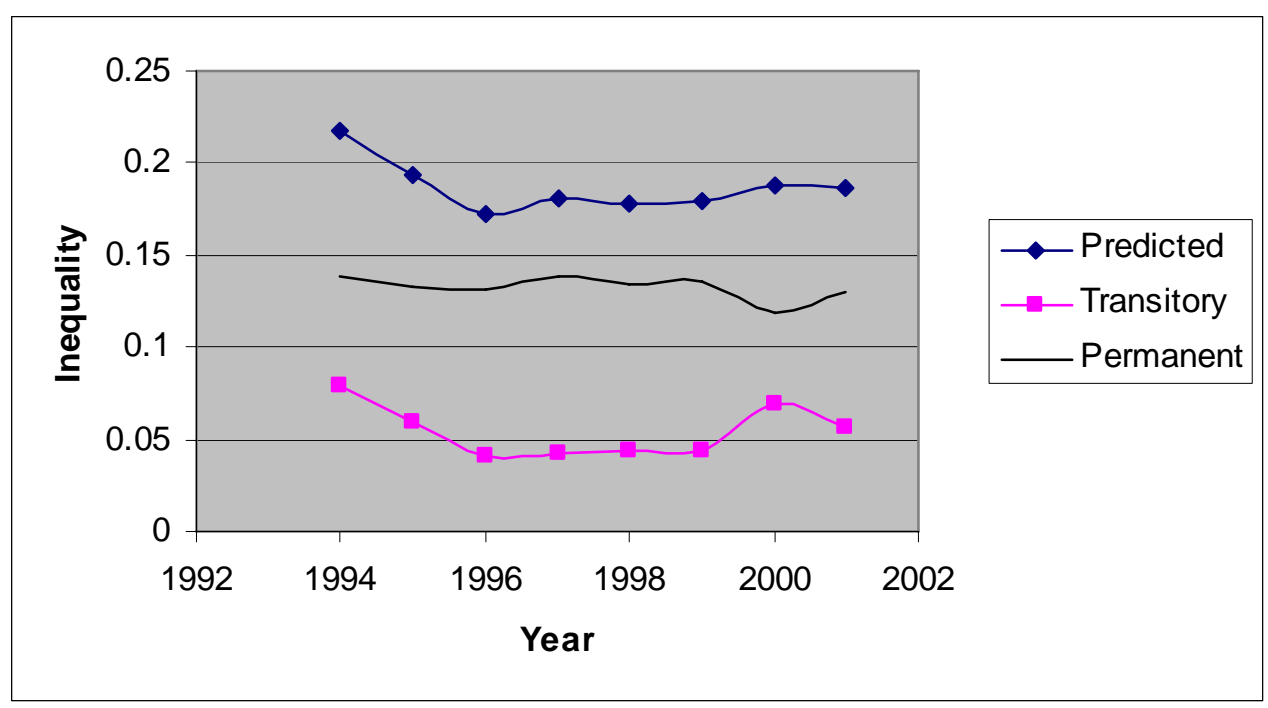

